\title{
MS2 Virus-like Particle as an Efficient Drug Delivery Tool: Optimizing the Synthesis and Purification Protocol
}

\author{
Khadijeh Hashemi \\ Ferdowsi University of Mashhad \\ Mohammad Mahdi Ghahramani Seno \\ Hospital for Sick Children \\ Mohammad Reza Ahmadian \\ Heinrich-Heine University \\ Bizhan Malaekeh-Nikouei \\ Mashhad University of Medical Sciences \\ Mohammad Reza Bassami \\ Ferdowsi University of Mashhad \\ Hesam Dehghani \\ Ferdowsi University of Mashhad \\ Amir Afkhami-Goli ( $\sim$ a-afkhami@um.ac.ir) \\ Ferdowsi University of Mashhad
}

\section{Research Article}

Keywords: MS2 Virus-like particle, PEG precipitation method, Buffer, shRNA delivery

Posted Date: July 7th, 2021

DOI: https://doi.org/10.21203/rs.3.rs-667960/v1

License: (c) (i) This work is licensed under a Creative Commons Attribution 4.0 International License. Read Full License 


\section{Abstract}

Introducing bacteriophage MS2 virus-like particles (VLPS) as gene and drug delivery tools increases the demand for optimizing their production and purification procedure. PEG precipitation method is used efficiently to purify VLPs, while the effects of pH and different electrolytes on the stability, size, and homogeneity of purified MS2 VLPs, and the encapsulated RNA sequences remained to be elucidated.

In this regard, a vector, capable of producing VLP with an shRNA packed inside was prepared. The resulting VLPs in different buffers/solutions were assessed for their size, polydispersity index, and ability to protect the enclosed shRNA. We report that among Tris, HEPES, and PBS, with or without NaNO3, and also NaNO3 alone in different $\mathrm{pH}$ and ionic concentrations, the 100mM NaNO3-Tris buffer with $\mathrm{pH}: 8 \mathrm{can}$ be used as a new and optimal MS2 VLP production buffer, capable of inhibiting the VLPs aggregation. These VLPs show a size range of 27-30nm and suitable homogeneity with minimum 12-month stability at $4^{\circ} \mathrm{C}$. Moreover, the resulting MS2 VLPs were highly efficient and stable for at least 48 hours in conditions similar to in vivo. These features of MS2 VLPs produced in the newly introduced buffer make them an appropriate candidate for therapeutic agents' delivery.

\section{Introduction}

Delivering small organic or inorganic molecules into the biological systems for therapeutic and research purposes has always been a challenge for biologists. In addition to natural barriers challenging the reach of the target organ and further, inside the cells, the stability of the material of interest to be delivered and that of the delivering agent, plus their safety and toxicity levels introduce additional limitations and challenges. In this line, various approaches such as those involving nanoscale platforms have been tested to find optimal delivery agents ${ }^{1,2}$. Viruses have naturally evolved optimal and efficient targeted cargo delivery and, hence, have successfully been used by biologists for the same purposes. However, nearly all of the naturally occurring viruses that may be most suitable for a specific cargo delivery purpose are also pathogenic and/or posing other threats. Therefore, various modifications are applied to a virus before it could safely be used as a vector. Virus-like particles (VLPS), which are frequently used by biologists for targeted and efficient cargo delivery, are viral particles normally devoid of considerable pathogenicity. ${ }^{3,4}$. The MS2 VLP is a $27 \mathrm{~nm}$ spherical RNA bacteriophage virus-like particle, consisting of 180 identical 129-amino acid coat protein subunits of $\sim 14 \mathrm{kDa}$ that form the icosahedral face for a $\mathrm{T}=3$ surface lattice ${ }^{5-7}$. MS2 VLP due to its small size and special shape, as well as its ability to encapsulate different nucleic acids, proteins, and other small molecules, and its endocytic route of entry has been considered a suitable vector for delivering into and tracking cargoes in the targeted cells ${ }^{8}$. The coat proteins of MS2 VLP can be recombinantly expressed and assembled in bacteria and yeasts ${ }^{9-12}$. It is conveniently prepared, packaged, delivered, and has high safety margins. Thus, the MS 2 VLP has been used as a potential medicinal carrier ${ }^{13}$ for the treatment of various diseases such as prostate cancer ${ }^{14}$, hepatocellular carcinoma ${ }^{15,16}$, and other diseases ${ }^{8,17-20}$. It has also been used for various research purposes including the investigation of RNA trafficking in live cells ${ }^{21}$, in platforms of vaccines and peptide epitope identification ${ }^{22-27}$, and quality control of DNA and RNA virus detection ${ }^{28-30}$.

It is well characterized that nucleic acids and other small molecules can be packaged in the MS2 VLP via their interaction with a short RNA stem-loop structure (19 nucleotides: pac site), which in turn binds to coat protein dimers ${ }^{5,31-33}$. Thus, the interaction with the $5^{\prime}$-terminus of the so-called pac site has been used as a preferred strategy to encapsulate different cargoes ${ }^{2,8}$. In this respect, it is very important to understand the behavior and assembly of virus-like particles and their aggregation and stability in different conditions. To make efficient VLPS, various physicochemical factors such as pH, temperature, and ionic strength of the solution, the ideal size, homogeneity, and stability of produced VLPs, and their capability to protect cargoes from degradation need to be taken into account. Likewise, in the recombinant production of MS2 VLPs, upon the transformation of plasmids expressing MS2 coat protein and a part of maturase into the bacteria, the most appropriate pH and buffers to support the stability and homogeneity of VLPs are sought after ${ }^{12,34-36}$

Different studies have shown that the amounts of electrolytes are important factors for the assembly of MS2 bacteriophage and related VLPs $8,9,35$. On the other side, if we consider the $\mathrm{pH}_{\mathrm{c}}$ as a critical $\mathrm{pH}$ value of the buffer used for the production of particles, the values below and above $\mathrm{pH}_{\mathrm{C}}$ may lead to repulsive electrostatic interactions and stable suspension of VLPs ${ }^{9,37}$. It has been shown that MS2 VLP particles remain in the detached form at $100 \mathrm{mM}$ NaNO3 concentration of buffer solution, and the isolated forms of VLPs in low ionic strength (1mM and 10mM) of NaNO3 buffer were merely seen at a pH value near the isoelectric $\mathrm{pH}$ (between 3 and 4) ${ }^{9}$. In this study, we introduce a new and optimized buffer to prepare the most stable condition for VLPS. To simulate the in vivo conditions, we assess the stability of VLPs produced in this buffer after incubation in $50 \%$ FBS and at $37^{\circ} \mathrm{C}$ temperature. We report improved buffer conditions that are used for the preparation of VLPs with appropriate size, shape, and stability.

\section{Results}

\section{NaNO3-Tris (100mM, pH:8) buffer provides the best condition for shape, particle size consistency, and dispersity of VLPs.}

To confirm the expression of the coat protein of VLPs, 14kDa disassembled protein of purified MS2 VLPs was separated by electrophoresis on $12.5 \%$ acrylamide gel and detected using specific antibody and Western blot method. BL21 (DE3) bacterial lysate showed both monomers and dimers of coat protein (Supplementary. Fig. S1). 
The influence of different NaNO3 concentrations (1 mM and 100mM, pH:8) and pH values (7 and 8) were assessed in MS2 VLP expression, production, and purification by the PEG precipitation method. The reduction of NaNO3 concentration could increase the particle size to larger than $100 \mathrm{~nm}(p<0.001$, Fig. 1a), probably because of PEG aggregation around the MS2 VLPs or agglomeration of the VLPs. PDI values in the 100mM NaNO3 solution were lower than the values in the $1 \mathrm{mM} \mathrm{NaNO3}$ solution (Fig. 1b). While TEM results indicated the size and shape variation in the $1 \mathrm{mM}$ NaNO3 solution, the MS2 VLPs in the $100 \mathrm{mM}$ NaNO3 solution disclosed much more shape uniformity. The $1 \mathrm{mM}$ concentration of NaNO3 induced MS2 VLPS deformation (Fig. 1c).

Decreasing the $\mathrm{pH}$ of $100 \mathrm{mM}$ NaNO3 solution from 8 to 7 drastically increased the average size of particles (Fig. $1 \mathrm{~d}, p<0.0001)$. Also, the PDI values were increased in lower $\mathrm{pH}$ (Fig.1e). TEM analysis of VLPs at different time points (during 35 days after VLP preparation) indicated a reduction in the size and an increase in the uniformity of VLPs when the $100 \mathrm{mM}$ NaNO3 solution (with pH 7 or 8 ) was used (Fig.1f, g). Additionally, more negative zeta potential values were registered in 100mM NaNO3 $(\mathrm{pH}: 7)$ compared to $100 \mathrm{mM} \mathrm{NaNO} 3(\mathrm{pH}: 8)$ (Supplementary, Fig. S2). To investigate the cause of these changes, the $\mathrm{pH}$ of NaNO3 solution was evaluated through different time points during a 60 days period which showed the reduction of $\mathrm{pH}$ value from 8 to 5.5 (Fig.1h). pH values below 6, resulted in instability and dissociation of MS2 particles.

Considering the severe $\mathrm{pH}$ fluctuation of NaNO3 solutions, during MS2 VLP production and purification, different buffers were used to stabilize the pH-dependent changes in particle size and PDI. As shown in Figs. 2a and b, the type of buffer had a significant effect on the particle size and PDI. While particle size and PDI of VLPs produced in HEPES ( $\mathrm{pH}$ : 8) were higher than $1 \mu \mathrm{m}$ (out of range of detection), lowering the $\mathrm{pH}$ to 7.4 could reduce the size and expand its PDI variation between 0.05 to 0.33 . TEM analysis was performed on samples with particles smaller than $100 \mathrm{~nm}$ in size. The results showed more homogeneous particles in Tris buffer $(\mathrm{pH}: 8)$ compared to particles in PBS buffer (pH:7.4) (Fig. 2c, and Supplementary Fig. S3b).

To find a more effective and stable production buffer for PEG precipitation of VLPs, solutions of NaNO3 (100mM) in Tris (1M, pH: 7.4 and 8), HEPES (pH: 7.4 and 8), and PBS (pH:7.4) were examined. In general, NaNO3 addition to various buffers boosted the VLP preparation efficiency. Although the particles in NaNO3-HEPES ( $\mathrm{pH}: 7.4)$ were smaller than particles in NaNO3-HEPES ( $\mathrm{pH}: 8)$ (extremely large, out of range of detection), yet the size of particles in NaNO3-HEPES (pH:7.4) was bigger than the size of the native MS2 bacteriophage (27-30nm) (Fig. 2d). The average PDI value was about 0.31 for particles in NaNO3-HEPES (pH:7.4). In this case, suspensions of VLPs with particle sizes below 100nm were observed by TEM microscopy. Additionally, VLPs produced in NaNO3-Tris ( $\mathrm{pH}: 7.4)$ were much bigger than particles in NaNO3-Tris (pH: 8) ( $p<0.0001)$. VLPs in NaNO3-PBS ( $\mathrm{pH}: 7.4)$ displayed a much smaller size than the native MS2 bacteriophage (27-30nm). PDI measurement of VLPs produced in NaNO3-Tris (pH:7.4) showed a wide size distribution in comparison to VLPs in NaNO3-Tris ( $\mathrm{pH}$ : 8), which was also confirmed by TEM analysis (Fig. 2e and f). This discrepancy might be explained by the VLP instability in a narrow $\mathrm{pH}$ range, so that only small differences in pH may lead to MS2 VLP aggregation. Zeta potential could not be evaluated because of the buffering nature of HEPES, PBS, and Tris (Supplementary, Fig. S2).

\section{MS2 Virus-like particles produced in the NaNO3-Tris $(\mathrm{pH}: 8)$ were more stable than VLPs produced in the NaNO3 solution ( $\mathrm{pH}: 8)$.}

To assess the stability of VLP coat proteins in NaNO3 $(100 \mathrm{mM}, \mathrm{pH}: 8)$ solution and NaNO3-Tris (100mM, pH:8) buffer, protein concentration was measured by spectrophotometry. Protein concentration and the number of VLPs in NaNO3 (pH:8) solution decreased over time (1, 2, 3, 4, 7, and 12 months), while it was stable for VLPs in NaNO3-Tris $(\mathrm{pH}: 8)\left(\approx 40 \mathrm{mg} \mathrm{ml}^{-1}, \approx 9 \mathrm{e}+15\right)$ (Fig. 3a and b). Moreover, particle size assessment of VLPs in two different solutions noticeably indicated the narrow and remarkably homogeneous distribution of VLPs produced in NaNO3-Tris (pH:8) buffer (Fig. 3c, Supplementary, Fig. S3a).

Considering the RNA sequence packed in MS2 VLPs (Fig. 3e), we performed RT-PCR to evaluate the stability of these RNAs in NaNO3 (pH:8) and NaNO3-Tris ( $\mathrm{pH}: 8)$ solutions. Four amplicons $(99,138,177$, and $216 \mathrm{bp})$ were detected on $2 \%$ agarose gel. These amplicons for VLPs generated in NaNO3-Tris ( $\mathrm{pH}: 8)$ buffer were detectable for 12 months, while for VLPs produced in NaNO3 solution they were detected for 3 months (Fig. $3 \mathrm{~d}$ ).

\section{VLPs prepared in NaNO3-Tris buffer remained stable in the presence of serum}

To make an environment similar to in vivo condition and in favor of further using VLPs in pharmaceutical studies, MS2 VLP suspensions produced in NaNO3 (100mM, pH: 7 and 8) solutions and NaNO3-Tris (100mM, pH:8) buffer were incubated with different serum concentrations (10\%, 30\%, and $50 \%)$. While VLPs in NaNO3 (100mM, pH:7) had a bigger size than VLPs in the same buffer with $\mathrm{pH}: 8$, by rising serum concentrations, a decreasing trend of VLP size was observed which was an indicator of serum effects on PEG dispersity. In contrast, the size of VLPS prepared in NaNO3-Tris $(100 \mathrm{mM}, \mathrm{pH}: 8)$ buffer was stable in different serum concentrations (Fig. 4a, c, e, and Supplementary Fig. 4a, b, c). It has been shown that PDI values below 0.7 provide particle size distribution in the midrange ${ }^{38,39}$. Although the PDI values in all three experiments were below 0.45 and, in the midrange, the effect of different concentrations of serum on PDI variation was evident in NaNO3 (100mM, pH:7, and 8) solutions (Fig. 4b and d). These changes did not occur for the VLPs produced in NaNO3-Tris (100mM, pH:8) buffer, with values around 0.3 which are acceptable for drug delivery (Fig. 4f).

RNA extraction and RT-PCR experiments for VLP samples generated in NaNO3-Tris buffer $(\mathrm{pH}: 8)$ in the presence of $50 \%$ serum concentration revealed the existence of RNA sequences and their stability up to 48 hours at $37^{\circ} \mathrm{C}$ (Fig. $4 \mathrm{~g}$ ).

VLPs prepared in NaNO3-Tris buffer can efficiently enter the cells. 
To determine whether the VLPs prepared in NaNo3-Tris buffer could transduce the cells, we used of Neuro2A cell line as immature neuronal cells (neuroblastoma) which could not transfect easily. Immunocytochemistry was then performed using the MS2 bacteriophage coat protein antibody. Bright intense red spots seen after 1 hour, were then dispersed in the cytoplasm after 4 hours, indicating the VLP entrance and probable disassembly of the VLPs over time (Fig. 5)

Table 1

Primers and oligonucleotides used in this study

\begin{tabular}{|c|c|c|c|}
\hline name & Oligonucleotide sequence $\left(5^{\prime}-3^{\prime}\right)$ & $\begin{array}{l}\text { Products } \\
\text { (bp) }\end{array}$ & Application \\
\hline MS27.Fw & CGGGATCCTGGCTATCGCTGTAGGTAGCC & \multirow[t]{2}{*}{1680} & \multirow{2}{*}{$\begin{array}{l}\text { amplification } \\
\text { of MS } 2 \\
\text { bacteriophage } \\
\text { coat protein } \\
\text { sequence }\end{array}$} \\
\hline MS27.Rev & CCCAAGCTTATGGCCGGCGTCTATTAGTAG & & \\
\hline shRNA & GCCTACTCGAACCGTTGATTTCAAGAGAATCAACGGTTCGAGTAGGC & - & $\begin{array}{l}\text { Checking the } \\
\text { stability of } \\
\text { VLPs }\end{array}$ \\
\hline \multirow{5}{*}{$\begin{array}{l}\text { shRNA- } \\
4 p a c \\
\text { (sense) }\end{array}$} & AGATCTGGATCCGGCCTACTCGAACCGTTGATTTCAAGAGAATCAACGGTTCGAGTAGGCCATATGTAA & \multirow[t]{5}{*}{-} & \multirow{5}{*}{$\begin{array}{l}\text { shRNA } \\
\text { Packaging in } \\
\text { the VLPs }\end{array}$} \\
\hline & CGATCGTAATTGCCTAGAAAACATGAGGATTACCCATGTCTGCAGGTCGACTCTAGAAAACATGAGGAT & & \\
\hline & TACCCATGTCTGCAGGTCGACTCTAGAAAACATGAGGATTACCCATGTCTGCAGGTCGACTCTAGAAAAC & & \\
\hline & ATGAGGATTACCCATGTCTGCAGTATTCCCGGGTTCATTTACGTACTAGCATAACCCCTTGGGGCCTCTAA & & \\
\hline & ACGGGTCTTGAGGGGTTTTTTGGGTACC & & \\
\hline \multirow{5}{*}{$\begin{array}{l}\text { shRNA- } \\
4 \text { pac } \\
\text { (anti- } \\
\text { sense) }\end{array}$} & CCAAAAAACCCCTCAAGACCCGTTTAGAGGCCCCAAGGGGTTATGCTAGTACGTAAATGAACCCGGGA & \multirow[t]{5}{*}{-} & \multirow{5}{*}{$\begin{array}{l}\text { shRNA } \\
\text { Packaging in } \\
\text { the VLPS }\end{array}$} \\
\hline & ATACTGCAGACATGGGTAATCCTCATGTTTTCTAGAGTCGACCTGCAGACATGGGTAATCCTCATGTTTTC & & \\
\hline & TAGAGTCGACCTGCAGACATGGGTAATCCTCATGTTTTCTAGAGTCGACCTGCAGACATGGGTAATCCTC & & \\
\hline & ATGTTTTCTAGGCAATTACGATCGTTACATATGGCCTACTCGAACCGTTGATTCTCTTGAAATCAACGGTT & & \\
\hline & CGAGTAGGCCGGATCCA & & \\
\hline VLP.FW & CCTACTCGAACCGTTGATTTCAAGAG & \multirow{2}{*}{$\begin{array}{l}99,138 \\
177,216\end{array}$} & \multirow{2}{*}{$\begin{array}{l}\text { Checking the } \\
\text { stability of } \\
\text { VLPs }\end{array}$} \\
\hline VLP.Rev & TGCAGACATGGGTAATCCTCATG & & \\
\hline
\end{tabular}

\section{Discussion}

The MS2 VLP is well known amongst different researchers for its small size and great potential of being a promising gene and drug delivery platform $[8,14,15,17,23,37]$. In this study, we focused on the optimization of the buffers which are used in the precipitation and purification process of VLPs. The ability of different cargos to be encapsulated in VLPs without time-dependent degradation is of great importance ${ }^{4}$. Thus, the most appropriate buffer and its characteristics including $\mathrm{pH}$ and ionic strength were identified. Our results led to a new VLP preparation strategy using NaNO3-tris (100mM, pH:8). This buffer greatly enhanced the consistency (Fig. 3), homogeneity (Fig. 4e and f), and half-life of VLPs (Fig. 3d).

Along with VLP synthesis, various purification strategies such as dialysis ${ }^{2,9,31}$, density gradient by cesium chloride $2,4,8,41$, or sucrose ${ }^{2,42}$, and PEG precipitation methods have been examined by different researchers. In this study, we used PEG for VLP purification to avoid probable virus aggregation which has been reported in some examples of the $\mathrm{CsCl}$ purification method ${ }^{43,44}$. Indeed, between all the different purification protocols, polyethylene glycol (PEG) precipitation ${ }^{45}$, is the less-toxic and low-cost method, appropriate for purifying proteins from various protein sources 9,46 . Previous studies have shown that various physicochemical factors can affect the capsid stability and aggregation of VLPs [2, 9, 12, 29, 30, 33]. Among these, $\mathrm{pH}$ and ionic strength are the most important factors. $\mathrm{Na}+$ containing solutions are used as the most acceptable ionic solutions in the PEG precipitation method 2,9,47, considering the fact that in monovalent electrolytes such as $\mathrm{NaCl}, \mathrm{KCl}$, and $\mathrm{LiCl}$, aggregation of $\mathrm{MS} 2$ does not occur within a reasonable kinetic time frame, and MS2 was stable even at high salt concentrations ${ }^{35}$. Thus, we used the NaNO3 solution to prepare an appropriate ionic environment. The shape of VLPs was analyzed by the TEM method. Furthermore, the particle size and PDI were measured as pharmaceutical characteristics of particles that influence endocytosis and cellular uptake.

Irrespective of the purification method, the preparation of MS2 VLPs in two concentrations of NaNO3 solution (1 mM and 100mM) in different ranges of $\mathrm{pH}$ (2 to 7) revealed higher stability of VLPs in $100 \mathrm{mM} \mathrm{NaNO} 3(\mathrm{pH}: 7)$ because of its high electrolyte concentration ${ }^{2}$, pH effectiveness ${ }^{2}$, and minimum mobility ${ }^{47}$. Despite the previous studies showing the stability of virus nanoparticle suspension against aggregation in $\leq 1 \mathrm{M}$ NaCl for more than $10 \mathrm{~h}^{35}$, in this study, the same assessment of two concentrations at the stable pH:8 resulted in different sizes of VLPs (Fig. 1). While the VLPs in 
$100 \mathrm{mM}$ NaNO3 solution ( $\mathrm{pH}: 8)$ were smaller than those VLPs in $1 \mathrm{mM} \mathrm{NaNO3}$ solution (Fig. 1a and c, $p<0.001)$, PDI of these particles in both concentrations (Fig. 1 b) were in the moderate range $(0.1-0.3)$ which could be more acceptable for drug delivery.

The $\mathrm{pH}$ of the NaNO3 solution and concentration of ions drastically affects the stability and aggregation of particles. The pattern of these changes for MS2 bacteriophage is completely different from that of MS2 VLP ${ }^{9}$. VLPs produced in 100mM NaNO3 at pH,8 displayed a smaller size ( $p<$ 0.0001) compared to VLPs produced at pH,7 (Fig. 1d). However, even in 100mM NaNO3 solution (pH: 8) with a smaller size, the size of these VLPs (median: $69.28 \mathrm{~nm}$ ) is larger than MS2 bacteriophage (27-30nm). Observation of larger VLPs might have resulted from the presence of PEG on the surface of VLPs. Sixty days after VLP preparation in 100mM NaNO3 solution ( $\mathrm{pH}: 7)$, an electron microscopy assay revealed the presence of isolated and uniform VLPs, while immediately after preparation, VLPs were aggregated. Since MS2 VLPs are stable within a narrow pH range [2, 9, 29, 31, 42], a feasible explanation for VLP dissociation over time could be the decreasing trend of pH of NaNO3 solution from 8 to 5.5 (Fig. $3 f$ and g).

Tris (pH:8), HEPES (pH:7.2-7.4), and PBS (pH:7.4) buffers, alone or mixed with some electrolytes and chemicals such as MgSO4, NaCl, and EDTA in different molarities have been chosen in various protocols as a protective buffer for VLP preparation and storage [8, 24, 26, 38, 43-45]. Applying these buffers for MS2 VLP synthesis determined that the VLPs in Tris Buffer $(\mathrm{pH}: 8)$ are more uniform and smaller than VLPs in HEPES and PBS buffers (Fig. 2). Despite the uniformity of VLPs in Tris Buffer, these VLPs due to incomplete disassembly or inappropriate assembly are smaller (median: $19.96 \mathrm{~nm}$ ) than MS2 bacteriophage $(27-30 \mathrm{~nm}$ ). The dimeter of VLPs in the HEPES buffer at pH values of 7.4 and 8 are different. While the particles were larger than VLPs in Tris and PBS buffers at $\mathrm{pH}: 7.4$, the particle sizes were undetectable at pH:8 probably due to agglomeration of the VLPS (Fig. 2).

Considering the pivotal role of monovalent cations in VLP formation and stability ${ }^{35}$ and to improve the VLPs' synthesis process, we employed the new VLP formation strategy by mixing Tris, HEPES, and PBS buffers with NaNO3 (100mM final concentration). VLPs in Tris buffer (1M, pH:8) containing NaNO3 $(100 \mathrm{mM})$ displayed a similar size to MS2 bacteriophage which is the convenient size for delivering, whereas VLPs in the same buffer at pH: 7.4 showed the maximum size among all the newly developed buffers (Fig. 2d). Interestingly, adding NaNO3 as an electrolyte to the buffer decreased the size of VLPs, but did not cause a considerable inhomogeneity (Fig. 2e and f). Adding $\mathrm{CaCl}_{2}$ to the aqueous suspension of MS2 bacteriophage leads to the aggregation of virus nanoparticles ${ }^{35}$.

In line with the VLPs' time-lapse stability experiments, previous studies have determined that particles are stable just for 3-4 weeks in $10 \mathrm{mM}$ HEPES and $100 \mathrm{mM} \mathrm{NaCl}{ }^{40}$, and remain stable in PBS for $>3$ months ${ }^{8}$ at $4{ }^{\circ} \mathrm{C}$. Another study has shown that the stability period of MS2 VLP is at least 4 months at $-20{ }^{\circ} \mathrm{C}$ in PBS ${ }^{29}$. While VLPs in NaNO3 solution $(100 \mathrm{mM})$ are stable for 3 months at $4{ }^{\circ} \mathrm{C}$, preparation of VLPs in NaNO3-Tris buffer $(100 \mathrm{mM}, \mathrm{pH}: 8)$ can increase the stability period to more than 12 months (Fig. $3 \mathrm{~d}$ ). Protein concentration is a reasonable marker for evaluating VLP stability. Contrary to VLPs prepared in NaNO3 solution which were degraded over time, protein concentration remained invariable for 12 months in NaN03-Tris buffer (100mM, pH: 8) (Fig. 3a). The increased stability of VLPs makes them a suitable candidate to be used in vaccination and drug delivery.

VLP's behavior and stability in serum are the most critical parameters for delivery. A previous study has shown that MS 2 VLPs kept in serum at $4{ }^{\circ} \mathrm{C}$ display the best stability for 3 days ${ }^{29}$. On the other hand, the stability of some VLPs in the serum-containing medium at $37{ }^{\circ} \mathrm{C}$ for 2 hours does not affect VLP's aggregation or disassembly ${ }^{51}$. Increasing serum concentration in VLP suspension up to $50 \%$, inhibited VLPs from agglomeration. Although the reduction in VLP's diameter happens probably via serum protein interaction with VLP's coat protein or PEG's removal, increasing serum concentration of VLPs suspension in NaNO3-Tris $(100 \mathrm{mM}, \mathrm{pH}: 8)$ did not affect the size. Moreover, in the presence of $50 \%$ serum at $37{ }^{\circ} \mathrm{C}$, the shRNA sequence inside the VLPs was protected against degradation for 48 hours (Fig. 4g). These results besides the other characteristics of MS2 VLPs prepared and stored in NaNO3-Tris (100mM, pH: 8), and also the reliable cell entry properties, represents MS2 VLP as a good candidate for gene and drug delivery. Therefore, any attempt at optimizing its generation and enhancing the physicochemical properties would be very helpful. Our results demonstrate that using NaNO3-Tris $(100 \mathrm{mM}, \mathrm{pH}: 8)$ buffer in the process of MS2 VLPs formation, substantially increases the quality and stability of the generated VLPS.

\section{Material And Methods}

No animal was used in this study.

\section{MS2 VLP Plasmid construction and expression system}

MS2 VLP expression vector was prepared by amplifying the MS2 Coat and a part of maturase DNA sequences from the pMS27 Plasmid (BCCM/LMBP plasmid Collection, Cabri, Belgium) (Table 1) ${ }^{18}$. The amplified sequence was inserted in-frame into pACYCDuet plasmid (Novagen, Gibbstown, NJ, USA) through BamH1 and HindIII restriction enzyme (Thermo Fisher Scientific Inc., USA) sites. The oligonucleotide sequence encoding the shRNA sequence was designed by siRNA Wizard ${ }^{\mathrm{TM}}$ software (Invivogen, USA) (Table 1). The synthesized shRNA (Macrogen Inc., South Korea) fused to four repeats of MS2 bacteriophage pac sequence (Macrogen Inc., South Korea) was sub-cloned into the other multiple cloning sites of pACYCDuet plasmid through Bglll and Kpn1 restriction enzyme (Thermo Fisher Scientific Inc., USA) sites (Fig. 3e). This sequence (shRNA-4pac, 
Table 1) was used as a control RNA sequence with the ability to be packed into VLP in each step, plasmid construction was verified by Sanger sequencing (Macrogen Inc., South Korea) and was named the SC Duet.

The SC Duet plasmid was introduced into the BL21(DE3) strain of E. coli Bacteria as a prokaryotic expression system. The Ecoli BL21(DE3)-SC Duet was cultured in a terrific broth medium at $37^{\circ} \mathrm{C}$, supplemented with $34 \mu \mathrm{g} / \mathrm{ml}$ chloramphenicol (pACYCDuet antibiotic selection). The expression of the sequences was induced by $1 \mathrm{mM}$ IPTG (isopropyl $\beta$-D-1- thiogalactopyranoside, Thermo Fisher Scientific Inc., USA) at an OD $600=0.6$ for 16 hours at $22{ }^{\circ} \mathrm{C}$. Bacteria were precipitated by centrifugation $\left(6000 \mathrm{~g}, 20 \mathrm{~min}, 4^{\circ} \mathrm{C}\right.$ ), and the derived precipitate was resuspended in the appropriate buffer (in $1 / 5^{\text {th }}$ of the initial bacterial culture volume). Lysozyme treatment $\left(0.05 \mathrm{mg} \mathrm{ml}^{-1}\right)$ was performed for 30 min at room temperature followed by sonication (total time: $3 \mathrm{~min}, 51 \mathrm{~W})$. Cell debris was collected by centrifugation $\left(13500 \mathrm{~g}, 20 \mathrm{~min}, 4^{\circ} \mathrm{C}\right)$. The supernatant containing VLPs was filtered through a $0.22 \mu \mathrm{m}$ membrane (Jet Bio-Filtration Co, China) and stored at $4{ }^{\circ} \mathrm{C}$ for further examination ${ }^{2}$. To eliminate cell debris, the suspension was filtered through a $0.1 \mu \mathrm{m}$ membrane (Sartorius, Germany) and then MS2 VLPs were purified according to the polyethylene glycol (PEG) precipitation method ${ }^{45}$. In brief, the precipitation of VLPs was performed by adding PEG (MW: 6000 , Sigma Aldrich, USA) at $10 \%$ of the final concentration (w/v) and $500 \mathrm{mM} \mathrm{NaCl}$. The suspension was incubated at $4{ }^{\circ} \mathrm{C}$ for $18 \mathrm{~h}$ and subsequently was centrifuged at $10000 \mathrm{~g}$ for $1 \mathrm{~h}, 4{ }^{\circ} \mathrm{C}$. The pellet containing MS2 VLPs was resuspended in the buffer used in the first step of purification (in $1 / 10^{\text {th }}$ of the initial resuspension volume). Eventually, this MS2 VLP suspension was filtered through a $0.22 \mu \mathrm{m}$ membrane (Jet Bio-Filtration Co, China). All MS2 VLP samples were kept at $4{ }^{\circ} \mathrm{C}$. Solutions of $1 \mathrm{mM}$, and 100mM NaNO3 (Merck \& Co., Inc. USA), 1M Tris (Sigma Aldrich, USA) buffer, and HEPES Buffer (Biowest, France) were prepared fresh, one day before experiments.

\section{MS2 VLPs disassembly and Western blot analysis}

To confirm the expression of VLP coat proteins, purified MS2 VLPs were disassembled by diluting $1: 2$ in $20 \mathrm{mM}$ cold glacial acetic acid for $1 \mathrm{~h}$ at $4{ }^{\circ} \mathrm{C}$. To precipitate the free nucleic acids, samples were centrifugated at $4{ }^{\circ} \mathrm{C}(16000 \mathrm{~g}, 20 \mathrm{~min})$. Then, we assessed the expression of coat protein by SDSPAGE (12.5\% acrylamide gel). Proteins were transferred to a $0.45 \mu \mathrm{m}$ nitrocellulose membrane (Bio-Rad Laboratories, Inc, USA). The membrane was blocked with $5 \%$ non-fat dry milk overnight at $4{ }^{\circ} \mathrm{C}$ and then incubated with a polyclonal Anti-Enterobacteria Phage MS2 coat protein antibody (1:7000 dilution, Millipore Sigma Co. USA) for 3 hours at room temperature. Incubation with HRP-labeled secondary antibody (1/18000 dilution, Abcam, USA) for 1 hour was performed to confirm the presence of 14 and $28 \mathrm{k}$ Da bands. The membrane was developed with Pierce ${ }^{\mathrm{TM}}$ ECL Western Blotting Substrate (Thermo Fisher Scientific Inc., USA). Signals were detected using the Chemiluminescence Detector system (G: BOX Chemi XT Analyser, SYNGENE, Eur.).

\section{Transmission electron microscopy}

The MS2 VLPs were diluted at 1:4 in the buffer. $10 \mu \mathrm{l}$ of samples were dropped onto carbon-coated copper grids and then were negatively stained by $2 \%$ uranyl acetate. After drying, VLPs were observed by transmission electron microscopy (Leo912AB, Germany) at $120 \mathrm{KV}$ at $4000 \mathrm{X}, 10000 \mathrm{X}$, 25000X, 31500X, 50000X, 63000X, and 80000X magnifications.

\section{Particle size, polydispersity index evaluation, and Zeta potential evaluation}

MS2 VLPs were diluted 1:4 in selected buffers and solutions. Particle size and polydispersity index (PDI) were measured by particle size analyzer (Vasco3-Cordouan, France) based on Dynamic Light Scattering (DLS) at $25^{\circ} \mathrm{C}$. Samples were analyzed by cumulants analysis of 5 consecutive measurements.

Zeta potential for those samples which were not stored in Buffer was estimated by Zeta potential detector (Zeta compact-CAD, France) and reported as zeta potential $(\mathrm{mV})$ line plot at $25^{\circ} \mathrm{C}$. To ensure reliability, it has been performed at least three times.

\section{$\mathrm{pH}$ assessment}

The $\mathrm{pH}$ of all solutions and buffers were measured by a pH meter (Mettler Toledo Co., Switzerland), one day before the experiment. Evaluations were done in triplicates at $0 \mathrm{~h}, 3 \mathrm{~h}, 12 \mathrm{~h}, 24 \mathrm{~h}, 7$ days, and 1-month time points.

\section{Protein spectrophotometry and MS2 VLPs measurement}

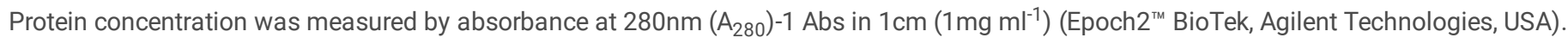
Measurements were performed three times at different time points (1, 2, 3, 4, 7, and 12 months). According to the protein concentration and the molecular mass of each VLP particle ( $14 \mathrm{kDa}$ per coat protein $x 180$ coat proteins per VLP $=2520 \mathrm{kDa}$ ), the number of VLPs in $100 \mathrm{mM}$ NaNO3 solution and NaNO3-Tris buffer $(\mathrm{pH}: 8)$ was calculated:

Each VLP molecular mass $=2520 \mathrm{kDa}=4.18 \mathrm{e}-15 \mathrm{mg}$

Number of VLPs (in each milliliter) = protein concentration of VLP suspension $\left(\mathrm{mg} \mathrm{ml}^{-1}\right) / 4.18 \mathrm{e}-15$ 
To determine MS2 VLP's stability in biological conditions, samples were mixed with fetal bovine serum (Biowest, France) (1:1), incubated in $37{ }^{\circ} \mathrm{C}$ for $2,4,6,8,10,12,24$, and $48 \mathrm{~h}$, and then stored in $-80^{\circ} \mathrm{C}$ for further RNA isolation, reverse transcription, and PCR. Furthermore, MS2 VLPs were also incubated in different serum concentrations $(10,30,50 \%)$ for 1 hour at $4{ }^{\circ} \mathrm{C}$ and particle size and PDI were evaluated diluting $1: 4$ with additional buffer.

\section{RNA extraction, reverse transcription, and polymerase chain reaction}

300ul of MS2 VLP suspension in different solutions or buffers (after purification by PEG precipitation method) were subjected to RNA isolation using the Total RNA Isolation Kit (DENAzist Asia Co., Iran) according to the manufacturer's instructions. The quantity of RNA was determined by a spectrophotometer (spectroEpoch2 ${ }^{\text {TM }}$ BioTek, Agilent Technologies, USA). A total of $1 \mu \mathrm{g}$ RNA was used for cDNA synthesis using random hexamer and MMLV reverse transcriptase (Thermo Fisher Scientific Inc., USA). To identify and check the integrity of shRNA-4pac RNA, polymerase chain reactions were carried out by Taq DNA Polymerase Master Mix (Ampliqon, Denmark) and designed primers (Table 1). Polymerase chain reaction steps were $94^{\circ} \mathrm{C}$ for $5 \mathrm{~min}$, followed by 35 cycles of $30 \mathrm{sec}$ at $94^{\circ} \mathrm{C}, 15 \mathrm{sec}$ at $70{ }^{\circ} \mathrm{C}, 15 \mathrm{sec}$ at $72{ }^{\circ} \mathrm{C}$, and a final extension period of 10 min at $72{ }^{\circ} \mathrm{C}$. PCR products were run on $2 \%$ agarose gel.

\section{Cell culture and Immunocytochemistry}

To confirm the VLP entrance, Neuro2A cells (Mouse Neuroblastoma cell line, ATCC) were cultured in Dulbecco's modified minimal essential medium (DMEM, low glucose) (Gibco: Thermo Fisher Scientific, USA) containing 10\% (v/v) of FBS (Gibco: Thermo Fisher Scientific, USA) and 1\% penicillin/streptomycin (Biowest, France) at $37^{\circ} \mathrm{C}, 5 \% \mathrm{CO} 2$ and $95 \%$ humidity. Cells were grown on poly D-lysine (Sigma Aldrich, USA) coated coverslips in four groups (1 hour and 4hours after VLP treatment, sham (without VLP), and blank negative control (with VLP treatment and without primary antibody). Briefly, cells were treated with $0.05 \mu \mathrm{g} / \mathrm{ml}$ of VLP suspension 24 hours after seeding. The cells were fixed by $2 \%$ paraformaldehyde (w/v) for $10 \mathrm{~min}$ at room temperature. Subsequently, after washing with cold PBS, the cells were permeabilized with $0.25 \%$ Triton X-100 in PBS) for $10 \mathrm{~min}$ at room temperature and blocked with PBS containing 1\% BSA. Cells were then incubated with primary antibody (anti- Enterobacteria Phage MS2 coat protein, 1:5000, Millipore Sigma Co. USA) for 3 hours at room temperature. The coverslips were washed with cold PBS and then incubated for 1 hour at room temperature in darkness with a secondary antibody (Monkey anti-rabbit Cy3 conjugated, 1:200, Jackson ImmunoResearch Laboratories Inc., USA). The coverslips were mounted on slides after washing with cold PBS. Stained cells were visualized using fluorescent microscopy (Nikon, Japan).

\section{Statistical analysis}

Data analysis was performed by GraphPad Prism (version 8.0.2, GraphPad Software Inc., CA). Results were analyzed using the Mann-Whitney and Kruskal Wallis test analysis.

\section{Abbreviations}

PEG: polyethylene Glycol, VLP: Virus-Like Particle, shRNA: short hairpin RNA, PDI: Poly Dispersity Index, TEM: Transmission Electron Microscopy, RTPCR: Reverse transcription-polymerase chain reaction

\section{Declarations}

\section{Acknowledgments}

The authors would like to thank Mrs. Fatemeh Khakrah for helping us with the particle size assessments and Mrs. Fereshteh Naseri for her technical assistance with the electron microscopy.

\section{Availability of Data and Materials}

The datasets used and/or analyzed during the current study are available from the corresponding author on reasonable request.

\section{Funding}

This work was supported by the Ferdowsi University of Mashhad under Grant 37672.

\section{Authors' Contributions}

KH: Conceptualization, Investigation, Formal analysis, Methodology, Writing- Original Draft, MMGS.: Writing- Review and editing, MRA.: WritingReview and editing, Resources, BM-N: Writing- Review and editing, Formal analysis, MRB: Conceptualization, HD: Validation, Methodology, Writing- 
Review and editing, Resources, AA-G: Supervision, Project administration, Validation, Methodology, Formal analysis, Writing- Review and editing, Funding acquisition.

\section{Competing interest}

Other Authors do not have competing interest.

A patent on the NaNO3-Tris $(100 \mathrm{mM}, \mathrm{pH}: 8)$ Buffer has been filed in The Organization of Registration of Documents and Real Estate of Iran by the Ferdowsi University of Mashhad with Kh. Hashemi, H. Dehghani, and A. Afkhami-Goli as inventors.

\section{References}

1. Ma, Y., J.M.Nolte, R. \& Cornelissen, J. J. L. M. Virus-based nanocarriers for drug delivery. Adv. Drug Deliv. Rev. 64, 811-825 (2012).

2. Dika, C., Gantzer, C., Perrinab, A. \& Duval, J. F. L. Impact of the virus purification protocol on aggregation and electrokinetics of MS2 phages and corresponding virus-like particles. Phys. Chem. Chem. Phys. 15, 5691-5700 (2013).

3. Wojta-Stremayr, D. \& Pickl, W. F. Fluorosomes: Fluorescent Virus-Like Nanoparticles that Represent a Convenient Tool to Visualize ReceptorLigand Interactions. Sensors 13, 8722-8749 (2013).

4. Pasloske, B. L., Walkerpeach, C. R., Obermoeller, R. D., Winkler, M. \& DuBois, D. B. Armored RNA technology for production of ribonucleaseresistant viral RNA controls and standards. J. Clin. Microbiol. 36, 3590-3594 (1998).

5. Valegard, K., Murray, A. B., Stockley, P. G., Stonehouse, N. J. \& Liljas, L. Crystal structure of an RNA bacteriophage coat protein-operator complex. Nature 371, 623-626 (1994).

6. Stephanopoulos, N., Tong, G. J., Hsiao, S. C. \& Francis, M. B. Dual-surface modified virus capsids for targeted delivery of photodynamic agents to cancer cells. ACS Nano. 4, 6014-6020 (2010).

7. Valegrd, K., Liljas, L., Fridborg, K. \& Unge, T. N. The Three-Dimensional Structure of the Bacterial Virus MS2. Nature 345, 36-41 (1990).

8. Ashley, C. E. et al. Cell-Specific Delivery of Diverse Cargos by Bacteriophage MS2 Virus-Like Particles. ACS Nano. 26, 5729-5745 (2011).

9. Dika, C., Duval, J. F. L., Ly-Chatain, H. M., Merlin, C. \& Gantzer, C. Impact of Internal RNA on Aggregation and Electrokinetics of Viruses: Comparison between MS2 Phage and Corresponding Virus-Like Particles. Appl. Environ. Microbiol. 77, 4939-4948 (2011).

10. Rodríguez-Limas, W. A., Sekar, K. \& Tyo, K. E. Virus-like particles: the future of microbial factories and cell-free systems as platforms for vaccine development. Curr Opin Biotechnol. 24, 1089-1093 (2013).

11. Legendre, D. \& Fastrez, J. Production in Saccharomyces cerevisiae of MS2 virus-like particles packaging functional heterologous mRNAs. J. Biotechnol. 117, 183-194 (2005).

12. Stonehouse, N. J. \& Stockley, P. G. Effect of amino acids substitutions on the thermal stability of MS2 capsids lacking genomic RNA. FEBS Lett. 334, 355-359 (1993).

13. Fu, Y. \& Li, J. A novel delivery platform based on bacteriophage MS2 virus-like particles. Virus Res. 211, 9-16 (2016).

14. Li, J. et al. Messenger RNA vaccine based on recombinant MS2 virus-like particles against prostate cancer. Int. J. Cancer 134, 1683-1694 (2014).

15. Wang, G. et al. Novel miR-122 delivery system based on MS2 virus like particle surface displaying cell-penetrating peptide TAT for hepatocellular carcinoma. Oncotarget 7, 59402-59416 (2016).

16. Lee, E. B. et al. Liver-specific Gene Delivery Using Engineered Virus-Like Particles of Hepatitis E Virus. Sci. Rep. 9, 1-10 (2019).

17. Pan, Y. et al. MS2 VLP-based delivery of microRNA-146a inhibits autoantibody production in lupus-prone mice. Int. J. Nanomedicine 7, 59575967 (2012).

18. Pan, Y. et al. Development of a microRNA delivery system based on bacteriophage MS2 virus-like particles. FEBS J. 279, 1198-1208 (2012).

19. Yao, Y. et al. Using a Novel MicroRNA Delivery System to Inhibit Osteoclastogenesis. Int. J. Mol. Sci. 16, 8337-8350 (2015).

20. Thong, Q. X., Biabanikhankahdani, R., Ho, K. L., Alitheen, N. B. \& Tan, W. S. Thermally-responsive Virus-like Particle for Targeted Delivery of Cancer Drug. Sci. Rep. 9, 1-14 (2019).

21. Querido, E. \& Chartrand, P. Using Fluorescent Proteins to Study mRNA TraYcking in Living Cells. Methods Cell Biol. 85, 273-292 (2008).

22. Chackerian, B., Carmo Caldeira, J. d., Peabody, J. \& Peabody, D. S. Peptide Epitope Identification By Affinity-Selection On Bacteriophage MS2 Virus-like Particles. J Mol Biol. 409, 225-237 (2011).

23. Zhai, L. et al. A novel candidate HPV vaccine: MS2 phage VLP displaying a tandem HPV L2 peptide offers similar protection in mice to Gardasil9. Antiviral Res. 147, 116-123 (2017).

24. Sun, S., Li, W., Sun, Y., Pan, Y. \& Li, J. A new RNA vaccine platform based on MS2 virus-like particles produced in Saccharomyces cerevisiae. Biochem. Biophys. Res. Commun. 407, 124-128 (2011).

25. Beld, M. et al. Highly sensitive assay for detection of enterovirus in clinical specimens by reverse transcription-PCR with an armored RNA internal control. J. Clin. Microbiol. 42, 3059-3064 (2004). 
26. Pan, Y. et al. A Therapeutic Peptide Vaccine Against PCSK9. Sci. Rep. 7, 1-10 (2017).

27. Janitzek, C. M. et al. A proof-of-concept study for the design of a VLP-based combinatorial HPV and placental malaria vaccine. Sci. Rep. 9, 1-10 (2019).

28. Zhang, L. et al. A novel method to produce armored double-stranded DNA by encapsulation of MS2 viral capsids. Appl. Microbiol. Biotechnol. 99, 7047-7057 (2015).

29. Wang, S. et al. Preparation and evaluation of MS2 bacteriophage-like particles packaging hepatitis E virus RNA. FEMS Microbiol. Lett. 363, 1-6 (2016).

30. Zhan, S. et al. Armored Long RNA Controls or Standards for Branched DNA Assay for Detection of Human Immunodeficiency Virus Type 1. J. Clin. Microbiol. 47, 2571-2576 (2009).

31. Mastico, R. A., Talbot, S. J. \& Stockley, P. G. Multiple presentation of foreign peptides on the surface of an RNA-free spherical bacteriophage capsid. J Gen Virol. 74, 541-548 (1993).

32. Talbot, S. J., Goodman, S., Bates, S. R., Fishwick, C. W. \& Stockley, P. G. Use of synthetic oligoribonucleotides to probe RNA-protein interactions in MS2 translational operator complex. Nucleic Acids Res. 18, 3521-3528 (1990).

33. Peabody, D. S. The RNA binding site of bacteriophage MS2 coat protein. EMBO J. 12, 595-600 (1993).

34. Lago, H., Parrott, A. M., Moss, T., Stonehouse, N. J. \& Stockley, P. G. Probing the Kinetics of Formation of the Bacteriophage MS2 Translational Operator Complex: Identification of a Protein Conformer Unable to Bind RNA. J. Mol. Biol. 305, 1131-1144 (2001).

35. Mylon, S. E. et al. Influence of Salts and Natural Organic Matter on the Stability of Bacteriophage MS2. langmuir 26, 1035-1042 (2009).

36. Sugiyama, T., Hebert, R. R. \& Hartman, K. A. Ribonucleoprotein complexes formed between bacteriophages MS2 RNA and MS2 protein in vitro. J. Mol. Biol. 25, 455-463 (1967).

37. Duval, J. F., Merlin, J. \& Narayana, P. A. Electrostatic interactions between diffuse soft multi-layered (bio)particles: beyond Debye-Hückel approximation and Deryagin formulation. Phys. Chem. Chem. Phys. 13, 1037-1053 (2011).

38. Zetasizer Nano Series User Manual. (2004).

39. Encyclopedia of Spectroscopy and Spectrometry. (Elsevier, 2016).

40. Wu, M., Brown, W. L. \& Stockley, P. G. Cell-specific delivery of bacteriophage-encapsidated ricin A chain . Bioconjugate Chem. 6, 587-595. (1995).

41. Wei, B. et al. Development of an antisense RNA delivery system using conjugates of the MS2 bacteriophage capsids and HIV-1 TAT cell penetrating peptide. Biomed. Pharmacother. 63, 313-318 (2009).

42. Patel, K. G. \& Swartz, J. R. Surface Functionalization of Virus-Like Particles by Direct Conjugation Using Azide-Alkyne Click Chemistry. Bioconjug. Chem. 22, 376-387 (2011).

43. Hosokawa, M. et al. Preparation of purified, sterilized, and stable adenovirus vectors using albumin. J. Virol. Methods 103, 191-199 (2002).

44. Zolotukhin, S. et al. Recombinant adeno-associated virus purification using novel methods improves infectious titer and yield. Gene Ther. 6 , 973-985 (1999).

45. Nguyen, T. H. et al. The RNA core weakly influences the interactions of the bacteriophage MS2 at key environmental . Soft Matter 7, 1044910456 (2011).

46. Juckes, I. R. M. Fractionation of proteins and viruses with polyethylene glycol. Biochim. Biophys. Acta 229, 535-546 (1971).

47. Langlet, J., Gaboriaud, F., Gantzer, C. \& Duval, J. F. L. Impact of Chemical and Structural Anisotropy on the Electrophoretic Mobility of Spherical Soft Multilayer Particles: The Case of Bacteriophage MS2. Biophys. J. 94, 3293-3312 (2008).

48. Galaway, F. A. \& Stockley, P. G. MS2 Viruslike Particles: A robust, Semisynthetic Targeted Drug Delivery Platform . Mol. Pharm. 10, 59-68 (2013).

49. Wei, Y. et al. RNase-Resistant Virus-Like Particles Containing Long Chimeric RNA Sequences Produced by Two-Plasmid Coexpression System. J. Clin. Microbiol. 46, 1734-1740 (2008).

50. Chang, L. et al. Armored long non-coding RNA MEG3 targeting EGFR based on recombinant MS2 bacteriophage virus-like particles against hepatocellular carcinoma. Oncotarget 7, 23988-24004 (2016).

51. Jekhmane, S. et al. Virus-Like Particles of mRNA with Artificial Minimal Coat Proteins: Particle Formation, Stability, and Transfection Efficiency. Nucleic Acids Ther. 27, 159-167 (2017).

\section{Figures}


Figure 1
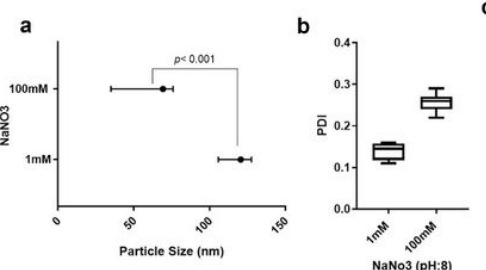

C i. $\mathrm{NaNO} 3(1 \mathrm{mM}, \mathrm{pH}: 8)$
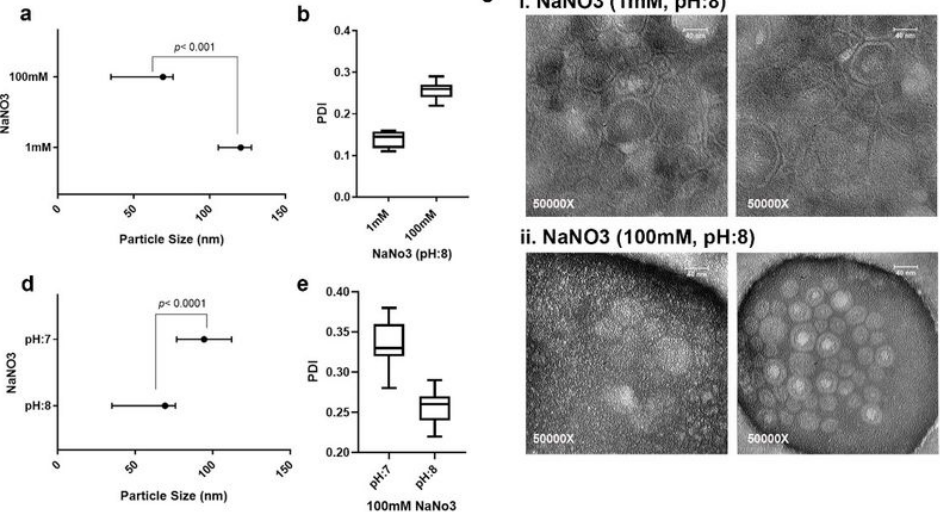

g

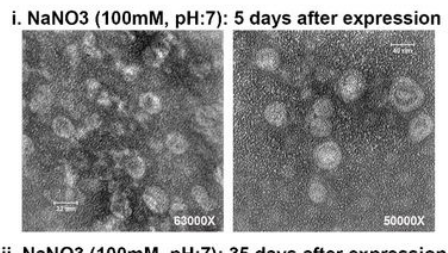

i. $\mathrm{NaNO} 3(100 \mathrm{mM}, \mathrm{pH}: 8): 5$ days after expression

ii. $\mathrm{NaNO} 3(100 \mathrm{mM}, \mathrm{pH}: 7)$ : 35 days after expression
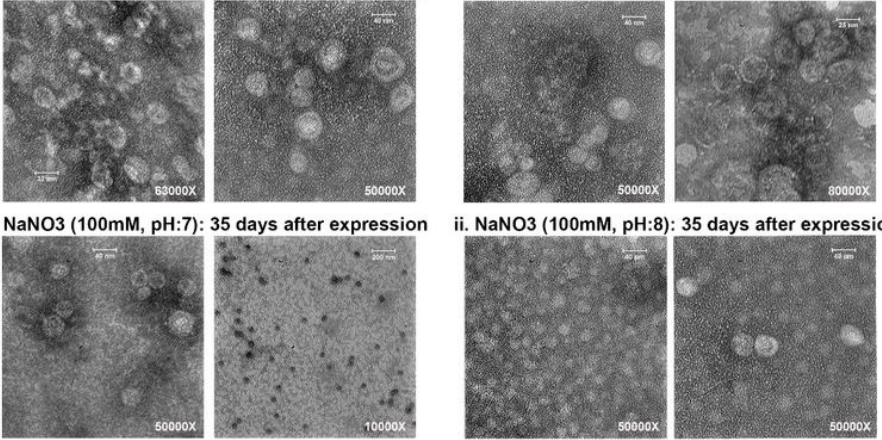

ii. $\mathrm{NaNO} 3(100 \mathrm{mM}, \mathrm{pH}: 8): 35$ days after expression

h $\begin{gathered}\text { pH fluctuation } \\ \text { (100mM NaNo3) }\end{gathered}$
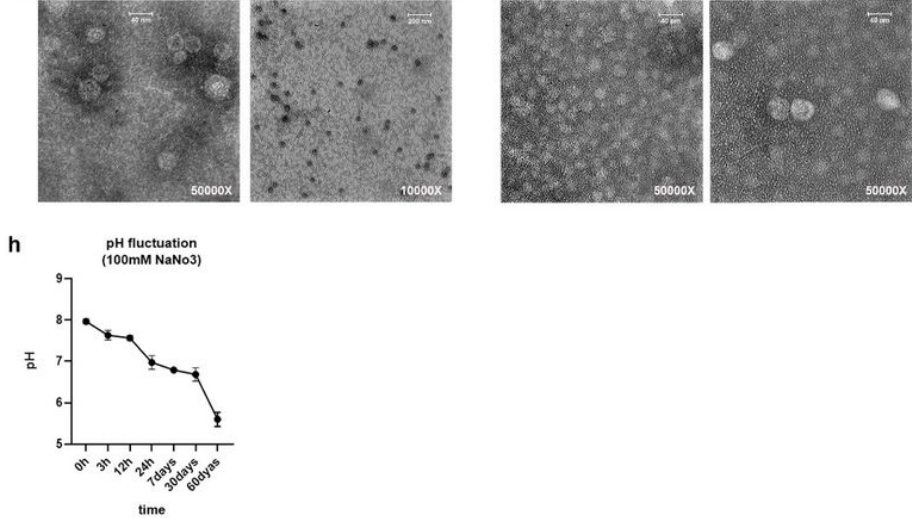

\section{Figure 1}

NaNO3-Tris (100mM, pH:8) buffer provides the best condition for shape, particle size consistency, and dispersity of VLPs. 


\section{Figure 2}
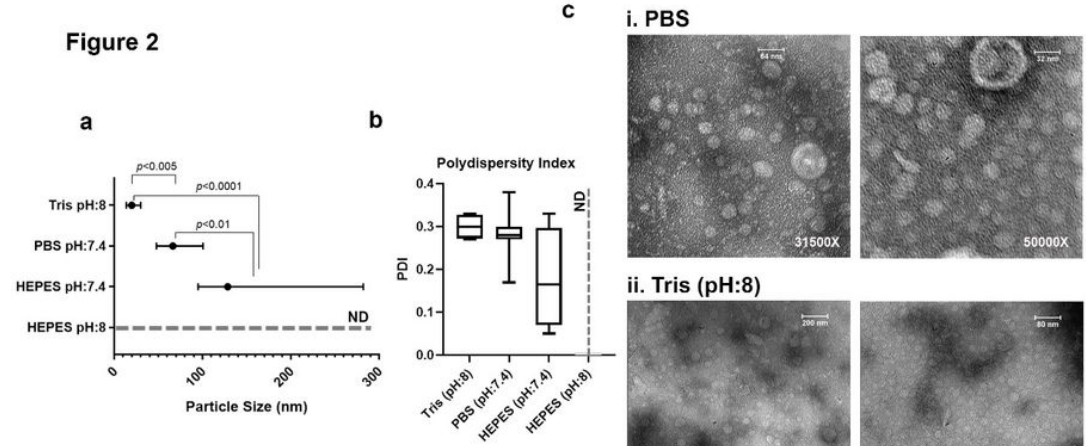

ii. Tris (pH:8)

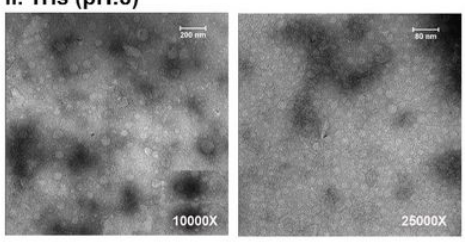

d
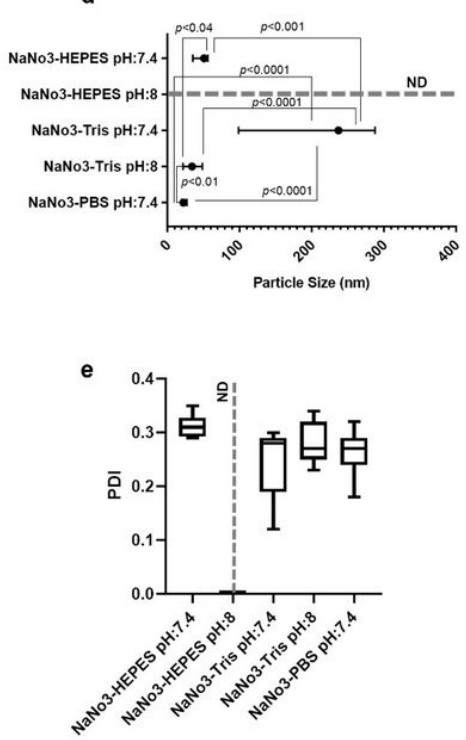

f

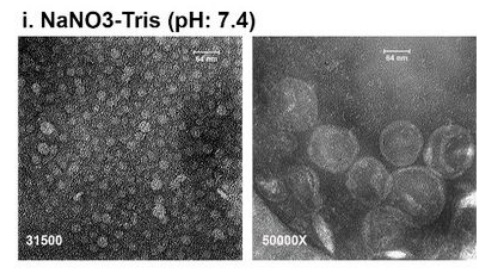

ii. NaNO3-Tris (pH: 8)

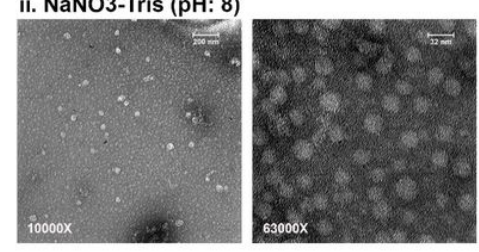

iii. NaNO3-PBS (pH: 7.4)
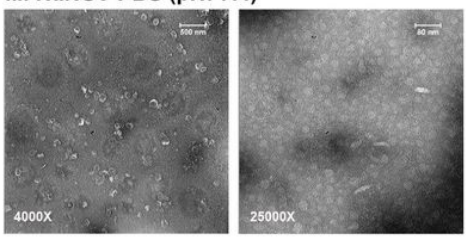

\section{Figure 2}

The severe $\mathrm{pH}$ fluctuation of NaNO3 solutions, during MS2 VLP production and purification, different buffers were used to stabilize the pH-dependent changes in particle size and PDI. 
Figure 3

a

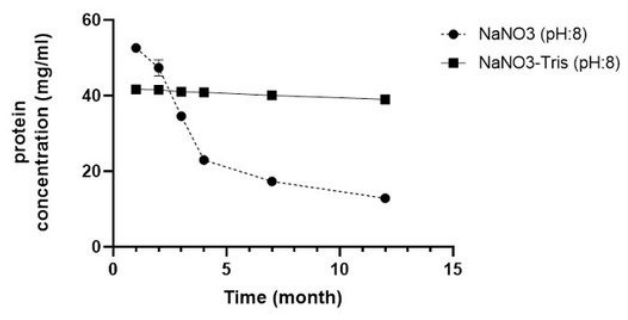

c

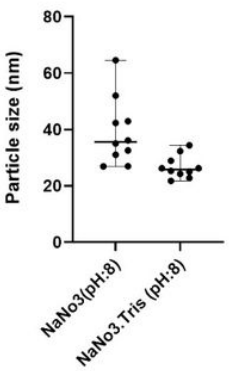

d
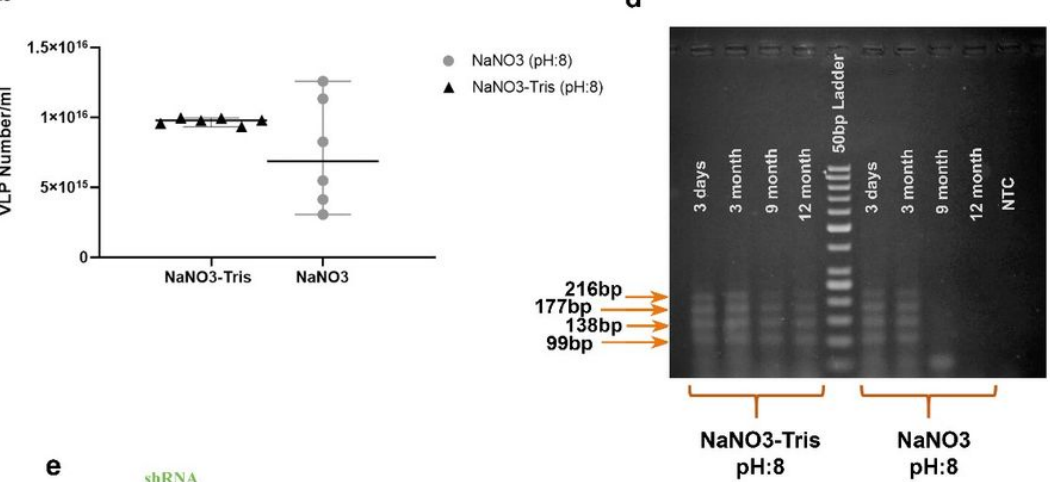

$\mathrm{NaNO} 3(\mathrm{pH}: 8)$

- NanO3-Tris (pH:8)

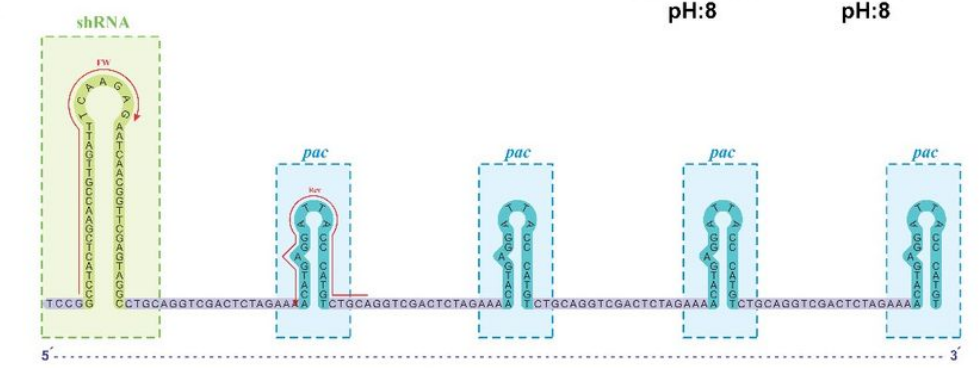

\section{Figure 3}

MS2 Virus-like particles produced in the NaNO3-Tris $(\mathrm{pH}: 8)$ were more stable than VLPs produced in the NaNO3 solution ( $\mathrm{pH}: 8)$. 


\section{Figure 4}
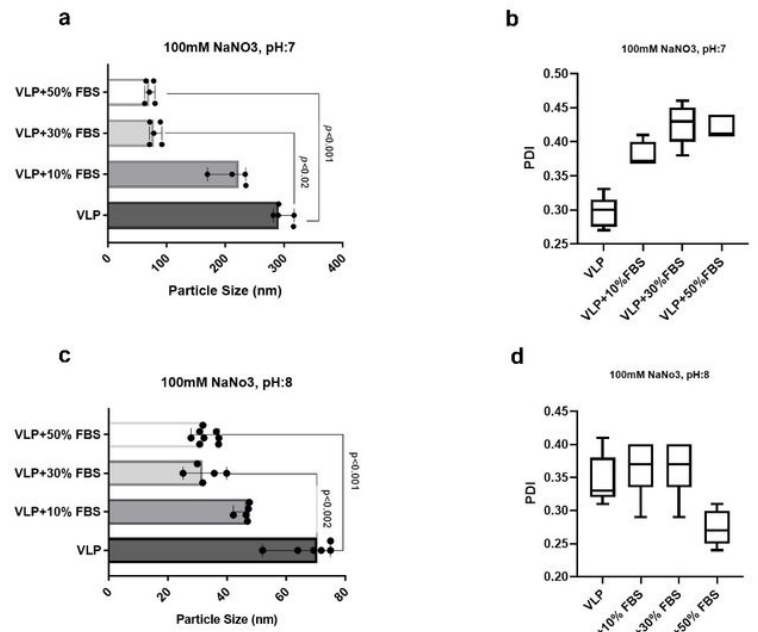

d
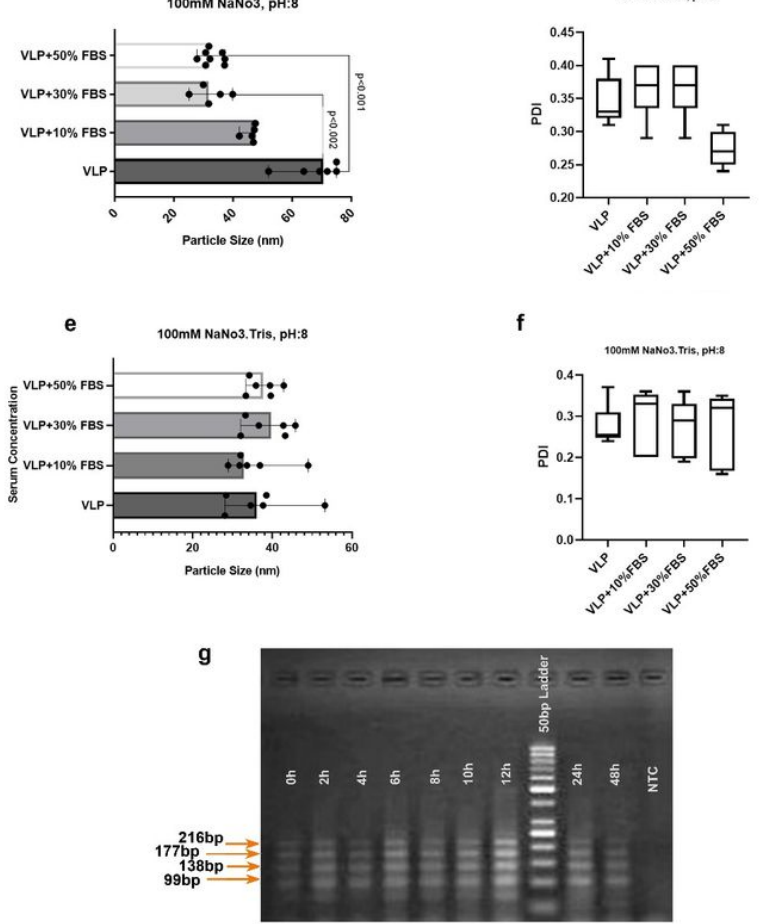

\section{Figure 4}

VLPs prepared in NaNO3-Tris buffer remained stable in the presence of serum 
Figure 5

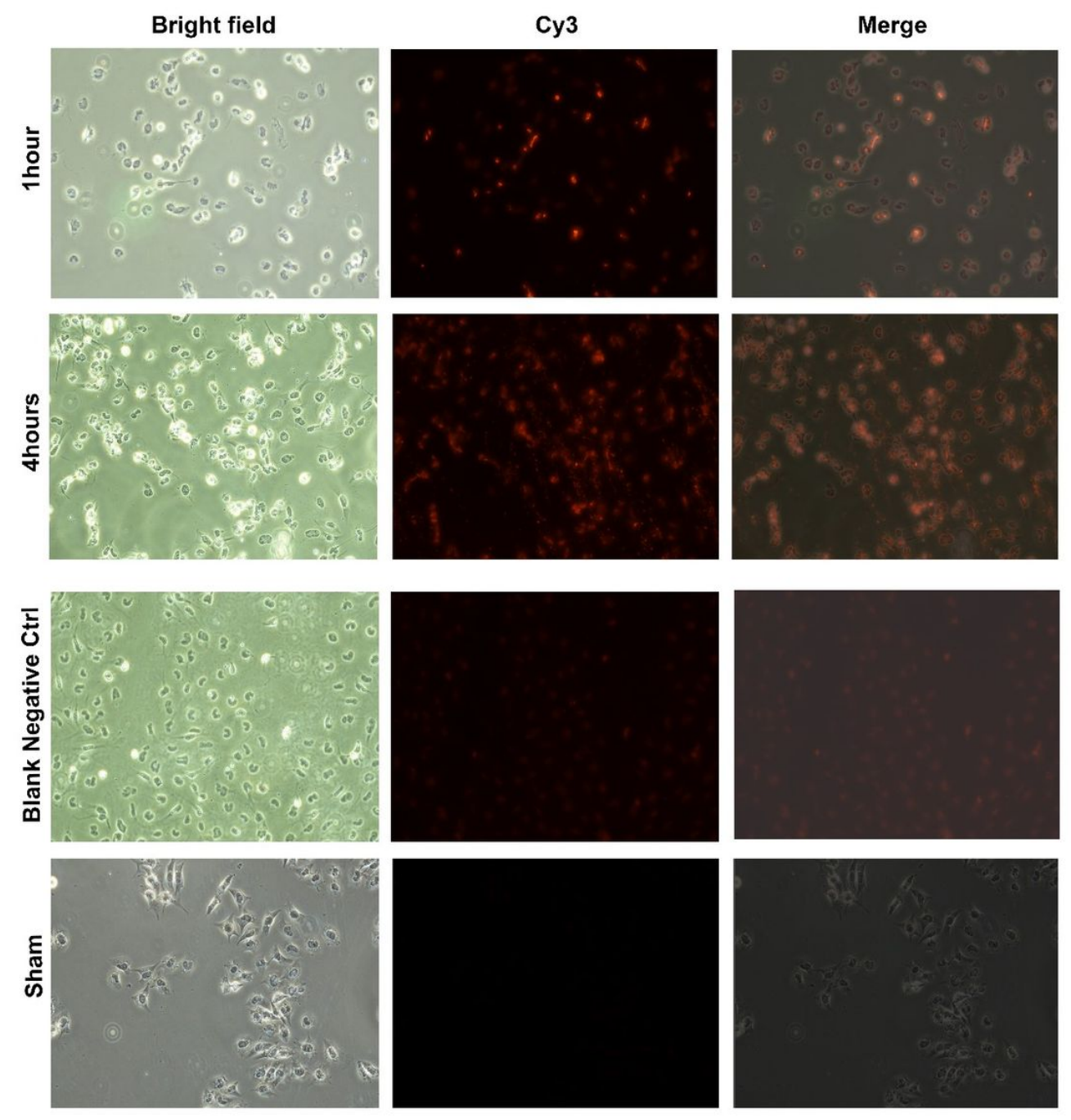

Figure 5

VLPs prepared in NaNO3-Tris buffer can efficiently enter the cells.

\section{Supplementary Files}

This is a list of supplementary files associated with this preprint. Click to download.

- Supplementary.pdf 